\title{
Analyzing Risk Factors for Brain Damages in a Group of Newborns with High Risk of Neurodevelopmental Sequelae: A Moroccan Study
}

\author{
S. Ait Malk \\ Service de médecine et réanimation néonatales, Centre National de Néonatologie et Nutrition, hôpital d'Enfants, \\ Centre hospitalier Ibn Sina, bd Ibn Rochd, Souissi 10100 \\ Rabat, Morocco
}

\section{MA. Radouani}

Service de médecine et réanimation néonatales, Centre National de Néonatologie et Nutrition, hôpital d'Enfants, Centre hospitalier Ibn Sina, bd Ibn Rochd, Souissi 10100

Rabat, Morocco

\section{Y. Taboz}

Unité mixte de recherche en Nutrition et alimentation URAC 39 université ibn tofail-CNESTEN RDC-Nutrition AFRA/AIEA

Kénitra, Morocco

H. Benkirane

Unité mixte de recherche en Nutrition et alimentation URAC 39, université ibn tofail-CNESTEN; RDC-Nutrition AFRA/AIEA

Kénitra, Morocco

H. Aguenaou

Unité mixte de recherche en Nutrition et alimentation URAC 39, université ibn tofail-CNESTEN; RDC-Nutrition AFRA/AIEA,

\section{Kénitra, Morocco.}

\section{Mrabet}

Equipe de recherche en santé et nutrition du couple mère enfant, Faculté de médecine et de pharmacie de RabatUniversité Mohammed V, Morocco Equipe de recherche en santé publique,

Faculté de médecine et de pharmacie de RabatUniversité Mohammed V Souissi,

Morocco.

\section{Amina Barkat (Corresponding author)}

Service de médecine et réanimation néonatales,Centre National de Néonatologie et Nutrition, hôpital d'Enfants, Centre hospitalier Ibn Sina, bd Ibn Rochd, Souissi 10100, Rabat, Morocco.

Equipe de recherche en santé et nutrition du couple mère enfant,

Faculté de médecine et de pharmacie de Rabat

Université Mohammed V, Morocco barakatamina@hotmail.fr 


\begin{abstract}
The aim of the study is to identify risk factors for occurrence of perinatal brain injury objectified in transfontanellar ultrasound (TFU) in a group of infants with high risk of neurodevelopmental sequelae. It's a retrospective study, conducted at the neonatal intensive care unit of the Children's Hospital of Rabat, during the period from 1 January to 31 December 2014. Were included newborns hospitalized for a medical condition with intrauterine croissance retardation (ICUR) more than 5 days and have survived. The neurological workup includes TFU made between day 2 and day 5 of life. Data analysis was performed on SPSS 18.0 software. The level of significance was $\mathrm{p}<0.05$. The percentage of newborns that developed neurological damage to the TFU was $36 \%$. Patients with abnormalities in the TFU had a breakdown time, duration dependence of O2, duration of hospitalization and a higher frequency of nosocomial infections than patients without abnormality. The interest in the prevention of nosocomial infections is to try to shorten the duration of invasive ventilation, favoring fast relay noninvasive ventilation.
\end{abstract}

Keywords: brain injury; newborns; prematurity, neurodevelopmental sequelae, trans-fontanellar ultrasound.

\section{Introduction}

With the many advances in neonatal resuscitation, and different government policies to reduce the level of infant mortality, we are faced with an increasing number of infants at high risk of neurological, sensorial and neurodevelopmental sequelae.

Advanced in perinatal intensive care have been associated with improved survival of high-risk neonates but have not resulted in decreased morbidity. Small sample sizes, heterogeneity of cohorts and methodology, diversity of perinatal clinical practice, and the high cost of randomized, controlled trials (RCTs) and follow-up care have all contributed to the lack of rigorous data on the sequelae of preterm delivery and the therapies used to improve the long-term outcome of high-risk infants.

The administration of oxygen and postnatal steroids are prime examples of interventions that may have immediate positive effects but negative long-term effects (Barrington, 2001). In addition, multicenter studies have identified significant center differences in the management and developmental outcome of high-risk infants (vohr, 2004).

In Morocco, a 2004 survey by the Ministry of Social Development, Family and Solidarity
$5.2 \%$ of the general population is considered disables. These disabilities have congenital or perinatal origin in $22.8 \%$ of cases according to the studies. Various pathologies involved are represented primarily by prematurity, low birth weight, neonatal infection, perinatal asphyxia, neonatal jaundice, congenital defects and metabolic disorders (www.social.gov.ma, 2010).

Progress was also made in the early detection of perinatal brain injury due to the transfontanellar ultrasound (TFU) and especially magnetic resonance imaging (MRI) whose access is not always easy especially in developing countries.

The objective of this study is to identify risk factors for perinatal brain injury objectified in TFU in a group of infants with high risk of neurodevelopment sequelae.

\section{Method}

This is a retrospective study, from medical records of newborns admitted to the neonatal intensive care unit at Children's Hospital of Rabat during the period 1 January to 31 December 2014. It included all patients who survived after a hospitalization duration greater than 5 days. Exclusion criteria were: 
patients who died and patients whose records were unusable.

A TFU was performed in patients at risk, between the second day (J2) and the fifth day (J5) of hospitalization. For premature, it was repeated every week until 37 weeks of corrected age.

The variables studied were as follows:

- Gestational age determined by the early fetal ultrasound, coupled with morphological examination (Dubowitz's score).

- Prematurity: defined as birth before 37 weeks of amenorrhea (SA)

- Intrauterine growth retardation (IUGR): defined by measurements (weight, height and head circumference lower than standard percentiles according to Leroy lefort curves)

- Perinatal asphyxia is defined by an Apgar score less than 7 at 5 minutes of life and the presence of neurological signs. It is classified into three stages according to Sarnat classification.

- Grade I: Minor encephalopathy with hypotonia and moderate hyperexcitability within 48 hours.

- Grade II: moderate encephalopathy with low consciousness, muscular hypotonia, abnormal movements and/or often seizures.

- Grade III: severe encephalopathy with coma and often loss of reflexes of the trunk.

- Nosocomial infection: Any infection which appears beyond 48 hours of hospitalization

-Enterocolitis: Inflammation of the bowel resulting clinically by hemorrhagic gastric residue, abdominal distension and the presence of radiological images. Radiography allows a classification of lesions according to Bell stages.
-Intraventricular hemorrhage (IVH): Four degrees:

Grade I: Isolated ubependymal hemorrhage.

Grade II: Moderate intraventricular hemorrhage with normal ventricles.

Grade III: Great abundance intraventricular hemorrhage with dilation of ventricles.

Grade IV: Intraventricular hemorrhage, hemorrhage grade III with intra-parenchymal extension type of periventricular hyperechogenicity.

- Antenatal maturative steroids: complete cure is defined by the administration of two doses of $12 \mathrm{mg}$ to 24 hours apart.

- Premature rupture of membranes (PRM): frank rupture of the amnion and chorion occurring before the start of delivery regardless of the term of pregnancy. It is pathological when the interval between rupture and delivery is more than 12 hours.

Data analysis were performed on Excel and SPSS 18.0 software. Quantitative variables were expressed as mean or median and interquartile range (M (IQ)). Qualitative variables were expressed as numbers and percentages. The comparison of variables was performed by the chi-square test, the averages, the Student test $t$ and Mann-Whitney test. The level of significance was $p<0.05$.

\section{Results}

The neonatal intensive care unit has hospitalized during the period 1 January to 31 December 2014, 640 newborns. Of this population, 122 had included, 97 were selected, representing $15.15 \%$ of hospitalized patients. 
Journal of Educational, Health and Community Psychology

Vol 5, No 1, 2016.

Malk, Radouni, Taboz, Benkirane, Aguenaou, Mrabet, Barkat

\section{Maternal data}

The synthesis of maternal data (Table 1) reveals that the average maternal age was $28.95 \pm 6.6$ years (range 17 to 47 years). Among the main pathologies noted, $30.6 \%$ of mothers had hypertension, $50 \%$ had genital or urinary tract infection and 19, $4 \%$ had other pathologies.

Table 1

Maternal characteristics of group born with high risk of neurodevelopment sequelae

\begin{tabular}{|c|c|}
\hline Maternal characteristics & Values $(\mathrm{N}=97)$ \\
\hline Maternal age (years) $(\mathrm{M} \pm \mathrm{SD})$ & $28,95 \pm 6,6$ \\
\hline Parity $(\mathrm{M} \pm \mathrm{SD})$ & $2,02 \pm 1$ \\
\hline Gravidity $(\mathrm{M} \pm \mathrm{SD})$ & $2,35 \pm 1,5$ \\
\hline $\mathrm{PIH}(\%)$ & $11(30,6 \%)$ \\
\hline Maternal infection (\%) & $18(50 \%)$ \\
\hline Others $(\%)$ & $7(19,4 \%)$ \\
\hline
\end{tabular}

$\mathrm{M} \pm \mathrm{SD} ;$ Average and standard deviation.

$\mathrm{PIH}$; pregnancy induced hypertension. \% ; percentage

Characteristics relating to pregnancy and childbirth

A preterm labor was observed in $57.7 \%$ of cases. The most represented mode of delivery was vaginal (67\%) (Table 2).

Table 2

Characteristics relating to pregnancy and childbirth group of newborns

with high risk of neurodevelopmental sequelae

\begin{tabular}{lll}
\hline $\begin{array}{l}\text { Features related to pregnancy } \\
\text { and childbirth }\end{array}$ & \multicolumn{2}{c}{$\begin{array}{c}\text { Values }(\mathrm{N}=97) \\
(\%)\end{array}$} \\
\hline TPB & 56 & $(57,7)$ \\
Followed pregnancy & 73 & $(75,3)$ \\
Antenatal steroids & 20 & $(20,8)$ \\
Vaginal issue & 65 & $(67)$ \\
Ceasaraen & 32 & $(33)$ \\
Plannified ceasaren & 10 & $(10,3)$ \\
Emergency ceasaren & 22 & $(22,7)$ \\
RPM & 26 & $(26,8)$ \\
Durée de RPM (heure) & 19 & $(4,72)$ \\
\hline
\end{tabular}

$\mathrm{M} \pm$ SD: Average and Standard Deviation.

TPB: Threatened Preterm Birth.

PRM : Premature rupture of membranes; \% :

percentage.

\section{Neonatal data}

In our series, there was a male predominance $(62.9 \%)$. The average weight was $2406,8 \mathrm{~g} \pm$ $995,6 \mathrm{~g}$ with a minimum of $1100 \mathrm{~g}$ and a maximum of $5000 \mathrm{~g}$. (Table 3). The main diseases that motivated hospitalization were represented by prematurity with $55.6 \%$ of cases, divided in very preterm birth in $23.3 \%$ of cases and moderate prematurity in $32.3 \%$ of cases; IUGR was noted in $24.7 \%$; Respiratory distress in $16,7 \%$ of cases with average of score of Silverman $4 \pm 2$. Perinatal asphyxia was present in $11,1 \%$ of the population, 7 patients had stage II of Sarnat 3 patients presented stage I. The temperature at the admission was $35.37 \pm 3.95^{\circ} \mathrm{C}$.

Table 3

Features of the new neonatal group born with high risk of neurodevelopmental sequelae

\begin{tabular}{|c|c|}
\hline Neonatal characteristics & $\begin{array}{l}\text { Values } \\
(\mathrm{N}=97)\end{array}$ \\
\hline Male & $61(62,9 \%)$ \\
\hline Female & $36(37,1 \%)$ \\
\hline Term (Weeks of amenorrhea) A \pm SD & $34,62 \pm 2,8$ \\
\hline Dubowitz (Weeks of amenorrhea) $\mathrm{A} \pm \mathrm{SD}$ & $34,99 \pm 2,6$ \\
\hline Birth Weight (gramm) $\mathrm{A} \pm \mathrm{SD}$ & $2407 \pm 996$ \\
\hline $\operatorname{Size}(\mathrm{cm}) \mathrm{A} \pm \mathrm{SD}$ & $45 \pm 5,4$ \\
\hline Cranial perimeter $(\mathrm{cm}) \mathrm{A} \pm \mathrm{SD}$ & $31,83 \pm 4,8$ \\
\hline Apgar 5 minutes : $3-7$ & $10(11,1 \%)$ \\
\hline Perinatal asphyxia & $10(11,1 \%)$ \\
\hline Prematurity & $54(55,6 \%)$ \\
\hline $\mathrm{RD}$ & $16(16,7 \%)$ \\
\hline
\end{tabular}

\section{Brain Injuries}

The TFU was performed in 82 patients. The percentage of infants who developed neurological damage to the trans-fontanellar ultrasound was $36 \%$. Twenty patients had ventricular hemorrhage, 14 newborns had a grade I, and 2 grades II, III and IV. Ten patients had other brain injuries, including 2 
cases of hydrocephalus, 3 cases of periventricular leukomalacia, 2 cases of hyperechoic lesions and 3 other injuries (subdural hematoma, parietal hematoma). The intraventricular hemorrhage was more common in premature infants with $31.8 \%$ in very premature infants, $29 \%$ in moderate or late preterm and $9.5 \%$ in full-term newborns (p 0.042).

\section{Support and other morbidities}

Antibiotherapy was indicated in $98 \%$ of cases, or before an unexplained prematurity, positive infectious history. Mechanical ventilation was required in $43.3 \%$ of patients with a median of 7 days of ventilation (5-10 days). The median dependence of $\mathrm{O} 2$ was 6 days (3-10 days). (Table 4). Morbidities during hospitalization were also dominated by nosocomial infections in $53.6 \%$ of patients. Enterocolitis was noted in $18.8 \%$ of patients. A case of premature retinopathy was noted.

Table 4

Care and neonatal morbidities

\begin{tabular}{ll}
\hline Characteristics of the support & $\begin{array}{l}\text { Values } \\
\mathrm{N}=97\end{array}$ \\
\hline Non invasive ventilation & $48(49,5 \%)$ \\
High flow nasal oxygen & $57(58,8 \%)$ \\
Ventilator & $42(43,3 \%)$ \\
Caffeine & $52(53,6 \%)$ \\
Hospitalisation's duration (day) A \pm SD & $13,13 \pm 8,2$ \\
Ventilation's duration(IQ) & $7,95(5-10)$ \\
Oxygendependacy duration (IQ) & $6(3-10)$ \\
Transfontanellar ultrasound TFU (\%) & \\
Normal & $51(62,2 \%)$ \\
Anormal & $30(36 \%)$ \\
Nosocomial infection & $52(53,6 \%)$ \\
Enterocolitis & $18(18,8 \%)$ \\
Intraventicular hemorrhagea & $20(21,1 \%)$ \\
Monitoring & $31(32 \%)$ \\
\hline
\end{tabular}

\section{Comparison brain injury in the initial TFU}

Patients with abnormalities in the TFU had a breakdown duration, dependence of oxygen and higher hospitalization than patients without abnormality and a higher incidence of nosocomial infections. (Table 5). There was no significant difference in the term and birth weight between the two groups. The comparison of decision antenatal steroids, caffeine, and indication of phototherapy showed no significant differences between the two groups.

\section{Discussion}

The majority of child disabilities originate in the perinatal period. Prematurity, perinatal asphyxia and intrauterine growth retardation are the main situations exposing children to the risk of perinatal disability.

Improved knowledge on the pathophysiology and mechanism of acquired brain injury during pregnancy and childbirth has better define the risk of impairments, disabilities and subsequent disorders (Marrett, 2004).

The risk factors of appearance of lesions in the TFU in our series are nosocomial infections and a breakdown of duration, oxygen dependence and higher hospitalization. In our patients with brain damage, nosocomial infection was more common $(70 \%)$. The diagnosis was made on the basis of clinical, inflammatory balance and radiological images. Infection is a major factor in the genesis of brain damage, not only in the prenatal period, but even after birth (Boog, 2005).

Leukomalacia seems to be triggered by infectious and inflammatory phenomena. They are likely via different mechanisms (cytokines, free radicals, excitotoxicity, apoptosis ...) lead to neuronal and / or glial cell death (Baud, 1998).

In recent years, the importance of the innate immune system receptors (Toll-like receptors) in the genesis of brain injury in neonatal sepsis has been demonstrated, with particular emphasis on Escherichia coli, coagulasenegative staphylococcus, and group B 
streptococcus in the premature neonates (Ballard, 2012).

Infants with both sepsis and necrotizing enterocolitis had a risk 4.6 times higher of seizures, suggesting a possible role of infection in the pathogenesis of brain injuries in premature infants. Thus, acquiring an infection during hospitalization increases the risk of brain damages, not only through the pro-inflammatory factors but also by hemodynamic disorders it causes (Kohelet, 2006 ; Berteloite, 2009).

The genesis of intracranial hemorrhage would be secondary to changes in cerebral blood flow (CBF). This risk is further increased in older premature due to the immature brain. Also, in our children with brain injuries, the most frequent use of assisted ventilation and oxygen dependence of the longer duration, can be explained by the severity of the neurological status, but also by the superimposed morbidity represented in our context by nosocomial infection, which often requires a fairly heavy resuscitation. All this will lead to an extension of hosptalization's duration which increases the risk of invasive procedures (nasal or buccal aspiration, tracheal aspirations and the poses of the central pathways) that are subsequently gateways for nosocomial infection. Also, several studies showed that long-term oxygen dependency or assisted ventilation, exposed to neurodevelopmental risks (Carlo, 2010 ; Bozet, 1996).

Other risks of brain injury factors have been identified in several studies: infection and the ante or perinatal inflammation (Berger, 2000), Chronic perinatal hypoxia (Berger, 2000; Wilson-Costello, 1998), male sex (Pharoah, 2002), twin's pregnancies, especially monochorial, and the death of a co-twin in utero (Scher, 2002), also in case of twin-totwin transfusion syndrome (TTS) (Cincotta, 2000), respiratory diseases, especially bronchopulmonary dysplasia (Majnemer, 2000), administration of postnatal steroids
(Doyle, 2001), and patent ductus arteriosus (Bozet, 1998).

The intraventricular hemorrhage was more common in very premature infants and in moderate prematurity in full-term neonates. The results of our study are similar with the results found in the literature (Larroque, 2003).

However, analyzing the risk factors of all brain injuries objectified, no difference was found for the small gestational age, intrauterine growth retardation and premature rupture of membranes. The sample size was not sufficiently representative would probably be the cause. Moreover, to antenatal steroids, studies report a decrease of almost $50 \%$ in the risk of intraventricular and periventricular hemorrhage in case of antenatal steroids administration (Baud, 1999). There would also have a beneficial effect on other inflammatory diseases such as necrotizing enterocolitis, or bronchopulmonary dysplasia. This has not been observed in our series probably related to the low rate of use.

\section{Conclusion}

The role of prematurity, the IGUR and perinatal asphyxia in the occurrence of serious deficiencies was confirmed in several studies. Our study also showed the involvement of morbidities superimposed during hospitalization, in particular nosocomial infection, duration of oxygen dependency, ventilation and prolonged hospitalization in the onset of brain damage in the population at risk.

These elements justify the interest of more aseptic techniques for the prevention of nosocomial infections; try to shorten the duration of invasive ventilation and thus the duration of oxygen dependency, favoring fast relay non invasive ventilation. 


\section{Declaration of interests}

The authors declare that they have no conflicts

of interest related to this article.

\section{References}

Barrington, KJ. (2001). The adverse neuro-developmental effects of postnatal steroids in the preterm infant: a systematic review of RCTs. BMC Pediatric, 1(1), 132-145.

Baud,O. \& Jarreau, P.H. (1999). Antenatal glucocorticoid treatment and cystic periventricular leukomalacia in very premature infants. N Engl J Med, 341, 1190-96.

Baud,O., Zupan,V.\& Lacaz, E. (1998). Periventricular leukomalacia-Masmonteil T. premature. Therapeutic Medicine / Pediatrics, 1(5), 409-18.

Berteloite, E. (2009). The consequences at school age of a former grand premature Memory for obtaining the State Diploma of Psychomotricien, Université Paul Sabatier Toulouse

Boog, G. (2005). Achieving the cerebral white matter of prematurity is generally related to infection and rarely with metabolic acidosis. Journal of Obstetrics Gynecology and Reproductive Biology, 34 (4), 410-411.

Bozet, C. (1998). Hearing Loss and prematurity: warning signs, diagnosis and monitoring Arch Pédiatr, 5(6), 690-693.

Carlo, W. A., Finer, N., N \& Walsh, MC (2010). Target ranges of oxygen saturation in preterm infants Extremely. New Engl J Med 362, 1959-1969.

Cincotta, R.B. \& Chan, F.Y. (2000). Long term outcome of twin-twin transfusion syndrome. Arch Dis Child Fetal Neonatal Ed, 83(3),171-176.

Disability Prevention Strategy in Morocco: www.social.gov.ma

Doyle, L.W. \& Casalaz, D. (2001). Outcome at 14 years of extremely low birth weight infants: a regional study. Arch Dis Child Fetal Neonatal Ed, 85(3), 159-164.

Kohelet, D. , Shohat, R., Lusky, A. \& Reishman,B. (2006). Israel Neonatal Network. Factoring risk for seizures in very low birthweight infants with periventricular Leukomalacia. $J$ Child Neurol, 21 (11), 965-70.

Larroque, B., Marrett, S. \& Ancel, P.Y. (2003). White matter damage and intraventricular hemorrhage in very preterm infants: the EPIPAGE study. J Pediatr, 143, 477-83.

Mallard,C. \& Wang, X. (2012). Infection-Induced Vulnerability of Perinatal Brain Injury. Neurol Res Int, 4, 102-153.

Majnemer, A. \& Coates, A.L (2000). Severe bronchopulmonary dysplasia increases risk for later neurological and motor sequelae in preterm survivors. Dev Med Child Neurol, 42(1), 53-60. 
Journal of Educational, Health and Community Psychology

Vol 5, No 1, 2016.

Malk, Radouni, Taboz, Benkirane, Aguenaou, Mrabet, Barkat

Marre, S. (2004).The indications for early intervention in the prevention and management of neurodevelopmental abnormalities. Pediatric Archives, 11(6), 611-613.

Pharoap, O. \& PLOMIN, R. (2002). Cerebral palsy in twins: a national study. Arch Dis Child Fetal Neonatal Ed, 7(2), 122-124.

Scher, A.I. , Blair, E. \& Ellenberg, J.H. (2002). The risk of mortality or cerebral palsy in twins: a collaborative population-based study. Pediatr Res, 52(5),671-681.

Wilson-Costello,D. \& Hack, M. (1998). Perinatal correlates of cerebral palsy and other neurologic impairment among very low birthweight children. Pediatrics, 102(2 Pt 1), 315-322.

Vohr, BR.Wright, LL. \& Dusick, A.M. (2004). Center differences and outcomes of extremely low birth weight infants. Pediatrics 113, 781- 789.

Table 5

Comparison of brain injury in transfontanellar ultrasound TFU

\begin{tabular}{|c|c|c|c|}
\hline Factors & $\begin{array}{l}\text { Neonates with anomaly in } \\
\text { TFU }(\mathrm{N}=30)\end{array}$ & $\begin{array}{l}\text { Neonates with normal } \\
\text { TFU }(\mathrm{N}=67)\end{array}$ & $\mathrm{P}$ \\
\hline Term A \pm SD & $34,27 \pm 2,98$ & $34,27 \pm 2,93$ & 0,99 \\
\hline Dubowitz's score $\mathrm{A} \pm \mathrm{SD}$ & $34,63 \pm 2,53$ & $34,61 \pm 2,5$ & 0,96 \\
\hline Weight ( gramm) & & & 0,809 \\
\hline$<1500$ & $5(17,2 \%)$ & $10(20,8 \%)$ & \\
\hline 1500 à 2500 & $13(48,8 \%)$ & $18(37,5 \%)$ & \\
\hline$>2500$ & $11(37,9 \%)$ & $20(41,7 \%)$ & \\
\hline APGAR 5,\% & & & 1 \\
\hline $3-7$ & $3(10,7 \%)$ & $4(8,5 \%)$ & \\
\hline$>7$ & $25(89,3 \%)$ & $43(91,5 \%)$ & \\
\hline Twins & $3(10 \%)$ & $20(41,7 \%)$ & 0,13 \\
\hline Ventilattion & $17(56,7 \%)$ & $18(35,3 \%)$ & 0,61 \\
\hline NIV & $18(60 \%)$ & $24(47,1 \%)$ & 0,28 \\
\hline Ventilation duration M(IQ) & $9(6 ; 13)$ & $6(4,75 ; 7,25)$ & 0,029 \\
\hline Oxygendependency duration M(IQ) & $9(6 ; 12,5)$ & $5(3 ; 7,5)$ & $<0,001$ \\
\hline Hospitalisation duration & 16 & 11 & 0,012 \\
\hline Nosocomial infection(\%) & $21(70 \%)$ & $21(41,2 \%)$ & 0,012 \\
\hline $\begin{array}{l}\text { Premature rupture of membranes } \\
(\%)\end{array}$ & $10(33,3 \%)$ & $15(29,4 \%)$ & 0,72 \\
\hline Enterocolitis (\%) & $9(30 \%)$ & $8(15,7 \%)$ & 0,12 \\
\hline Antenatal steroides $\%$ & $8(26,7 \%)$ & $11(22 \%)$ & 0,72 \\
\hline Caffeine $\%$ & $18(60 \%)$ & $31(60,8 \%)$ & 0,94 \\
\hline ICUR $(\%)$ & $8(26,7 \%)$ & $12(23,5 \%)$ & 0,75 \\
\hline Phototherapy (\%) & $13(43,3 \%)$ & $24(48 \%)$ & 0,68 \\
\hline
\end{tabular}

